\title{
Amyotrophic lateral sclerosis: glutamate dehydrogenase and transmitter amino acids in the spinal cord
}

\author{
Susanne Malessa, P Nigel Leigh, Oswald Bertel, Elfriede Sluga, Oleh Hornykiewicz
}

\begin{abstract}
Measurements were taken of the activity of glutamate dehydrogenase (GDH) and the levels of transmitter amino acids in anatomically dissected regions of cervical and lumbar spinal cord in eight patients dying with amyotrophic lateral sclerosis (ALS) and in 11 neurologically normal controls. GDH activity was considerably increased in lateral and ventral white matter and in the dorsal horn of the ALS cervical spinal cord, but normal in the ventral horn and the dorsal columns. Similar, although less pronounced, GDH changes were found in the lumbar enlargement. The mean concentrations of aspartate and glutamate were reduced in all regions of ALS spinal cord investigated. Taurine concentrations were significantly increased in several subdivisions of cervical spinal cord, but normal in lumbar regions. Glycine levels were significantly reduced in lumbar ventral and dorsal horns. There was no striking change in spinal cord GABA levels in our ALS patients. It is suggested that the reduced levels of glutamate and aspartate as well as the elevated GDH activity in the spinal cord of ALS patients may reflect an overactivity of the neurons releasing these potentially excitotoxic amino acids and thus may be causally related to the spinal neurodegenerative changes characteristic of ALS.
\end{abstract}

Institute of Biochemical Pharmacology University of Vienna, Vienna, Austria $S$ Malessa O Bertel O Hornykiewicz Institute of Psychiatry, Denmark Hill, London, UK $P$ N Leigh

Neurological Institute, University of Vienna, Vienna, Austria E Sluga

Correspondence to: Dr Malessa, Department of Neurology, University of Munich, Klinikum Grosshadern, Marchioninistrasse 15, 8000 Murchioninistrasse 15, 8000
Munich 70, Germany Munich 70, Germany and in final revised form 11 January 1991. Accepted 11 January 1991 reduced in leucocytes, fibroblasts and muscle mitochondria of patients with multiple system atrophy disorders, including some cases presenting as "atypical ALS", 8-10 but GDHactivity in leucocytes of typical ALS patients has been found to be normal, ${ }^{4}$ or decreased in a subgroup of patients. ${ }^{11}$ The specificity of the observations on GDH changes in leucocytes is doubtful since similar changes in GDH have been found in a variety of unrelated neurodegenerative disorders. ${ }^{1213}$

If changes in glutamate metabolism are relevant to the pathogenesis of ALS, it is important to establish whether the activity of GDH is altered in the central nervous system. We have therefore measured the activity of $\mathrm{GDH}$ and the concentrations of glutamate and other neurotransmitter amino acids in anatomically dissected subdivisions of cervical and lumbar spinal cord of ALS and control patients.

\section{Materials and methods}

PATIENTS AND CONTROLS

Segments of spinal cord of eight ALS patients and 11 controls were obtained at necropsy. The cervical spinal cord was available from 10 controls, four females and six males [mean (SD) age: 62 (3) years; mean post mortem delay: 17 (3) hours] and from seven ALS patients, six females and one male [mean (SD) age: 63 (3) years; mean post mortem delay: 30 (11) hours]. For measurements of aspartate, death-to-freezing intervals were matched (controls $\mathrm{n}=9: 13$ (2) hours; ALS $\mathrm{n}=5: 14$ (3) hours). Lumbar segments were obtained from six controls, three females and three males (mean age: 60 (5) years; mean post mortem delay 15 (2) hours) and four ALS patients, three females and one male (mean age: 60 (2) years; mean post mortem delay 15 (6) hours). Of five controls and three ALS patients both cervical and lumbar enlargements were available for study. Control patients had died of myocardial infarction (five patients), respiratory failure, carcinoma of the tonsils, carcinoma of the breast, leukaemia and melanoma. All ALS patients had died of respiratory failure. To our knowledge, none of the control patients had shown signs of neurological impairment. Seven ALS patients had been diagnosed by a neurologist as nonfamilial and one case as probably familial ALS following full clinical investigation. Histopathological examination excluded other causes of the neurological syndrome and showed depletion of anterior horn cells and 


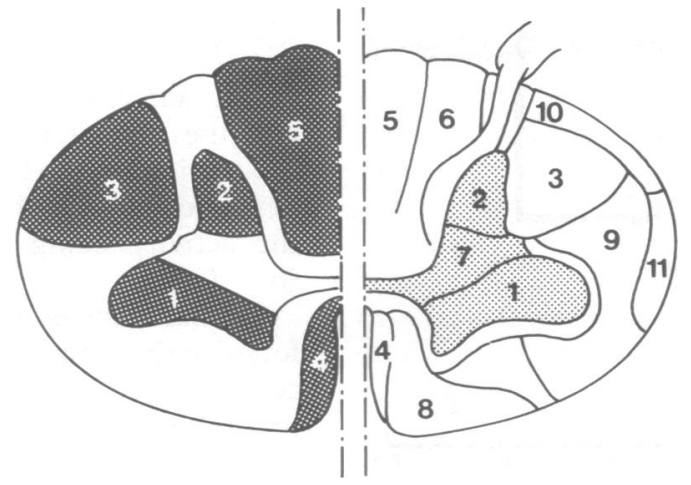

Figure 1 Schematic representation of the dissected regions (left) and corresponding anatomical structures (right) shown at the level of the cervical enlargement. Left half of figure: structures (numbers) and their abbreviations (in parenthesis): 1 : ventral horn (VH); 2: dorsal horn (DH); 3: lateral white matter (LWM); 4: ventral white matter (VWM); 5: dorsal white matter (DWM). Right half of figure: $1:$ ventral horn; $2:$ dorsal horn; 3: lateral corticospinal tract; 4: anterior corticospinal tract; 5: fasciculus gracilis; 6: fasciculus cuneatus; 7 : substantia intermedia; 8 : fasciculus longitudinalis medialis; 9: fasciculus anterolateralis; 10: tractus spinocerebellaris posterior; 11 : tractus spinocerebellaris anterior.

degeneration of the corticospinal tracts consistent with the clinical diagnosis. In addition, we analysed spinal tissue of one patient dying with progressive spinal atrophy, who is not included in the ALS group.

PREPARATION OF TISSUE HOMOGENATES

At necropsy, either whole spinal cords were placed on dry ice (ALS 1-3, controls 1-7) or identified segments of spinal cord comprising cervical and lumbar enlargements were frozen in isopentane/dry ice and stored at $-70^{\circ} \mathrm{C}$ until dissection. Transverse slices of 1-2 mm thickness were cut from cervical segments 6 and 7 and from the lumbar enlargement and dissected anatomically on a cold plate (ca $-10^{\circ} \mathrm{C}$ ) as shown in fig 1 . Corresponding left and right pieces were pooled, weighed and stored at $-70^{\circ} \mathrm{C}$ for several days. Samples were homogenised in 50 volumes of ice-cold Na-phosphate buffer $(50 \mathrm{mM}$, ph 7,5$)$ with a Branson sonicator. Aliquots were taken for estimations of protein and transmitter amino acids and the remaining homogenate diluted with the same Na-phosphate buffer to tissue concentrations of $1-0.25 \mathrm{mg}$ wet weight per $0 \cdot 1 \mathrm{ml}$ for measurements of GDH activity.

\section{ASSAY PROCEDURES}

GDH ASSAY GDH was measured in the direction of reductive amination of alphaketoglutarate as described by Schmidt. ${ }^{14}$ The reaction mixture contained $20 \mu \mathrm{l} 12 \mathrm{mM}$ NADH (Boehringer Mannheim), $20 \mu \mathrm{l}$ $100 \mathrm{mM}$ ADP (Sigma), $1.44 \mathrm{ml} 70 \mathrm{mM}$ triethanolamine hydrochloride ( $\mathrm{pH} \mathrm{8.0)}$ plus 3,5 mM EDTA, $60 \mu \mathrm{l} 3 \cdot 3 \mathrm{M}$ ammonium acetate and $300 \mu \mathrm{l} 50 \mathrm{mM} \mathrm{Na} \mathrm{NPO}_{4}$ buffer (pH 7.5). Whole homogenates $(0.1 \mathrm{ml}$, equivalent to $0.3-0.5 \mathrm{mg}$ wet weight) were added and the reaction started by the addition of $0.06 \mathrm{ml} 233 \mathrm{mM}$ alpha-ketoglutarate to a final volume of $2.0 \mathrm{ml}$. The rate of oxidation of
$\mathrm{NADH}$ at room temperature was measured with a Beckman spectrophotometer at $340 \mathrm{~nm}$. All samples were done at least in duplicate. The assay was performed on the day of homogenisation, since storage of homogenates at $-20^{\circ} \mathrm{C}$ overnight resulted in a variable loss of GDH activity. Pretreatment with Triton X $100(0.05$ and $0.1 \%)$ did not result in further activation of GDH. Enzyme activity appeared linear in tissue concentrations from $0 \cdot 1-1 \mathrm{mg}$. Measurements in independent assays using adjacent tissue slices varied less than $10 \%$.

AMINO ACIDS For estimation of neurotransmitter amino acids, aliquots of $0.03 \mathrm{ml}$ were diluted with $0.09 \mathrm{ml} 0.05 \mathrm{M}$ perchloric acid and centrifuged at $17000 \times \mathrm{g}$ for 15 minutes. In $20-40 \mu$ l of supernatant, corresponding to $0.10-0.20 \mathrm{mg}$ wet tissue, amino acids were analysed by means of high pressure liquid chromatography (HPLC) after post-column derivatisation by the fluorogenic reagent o-phthalaldehyde (OPT) as described by Schmid et al. ${ }^{15}$ Protein was determined by Lowry's method. ${ }^{16}$

Mean values of the control and the ALS group were compared with Student's $t$ test.

\section{Results}

\section{GDH ACTIVITY}

In cervical spinal cord of neurologically normal controls, highest GDH activity was found in the ventral grey matter $[2.17(0.2) \mu \mathrm{mol} / \mathrm{h} / \mathrm{mg}$ wet weight; mean (SEM) $\mathbf{n}=10$ ] followed by the dorsal horn $(1.58-0.09)$ (fig 2a). In white

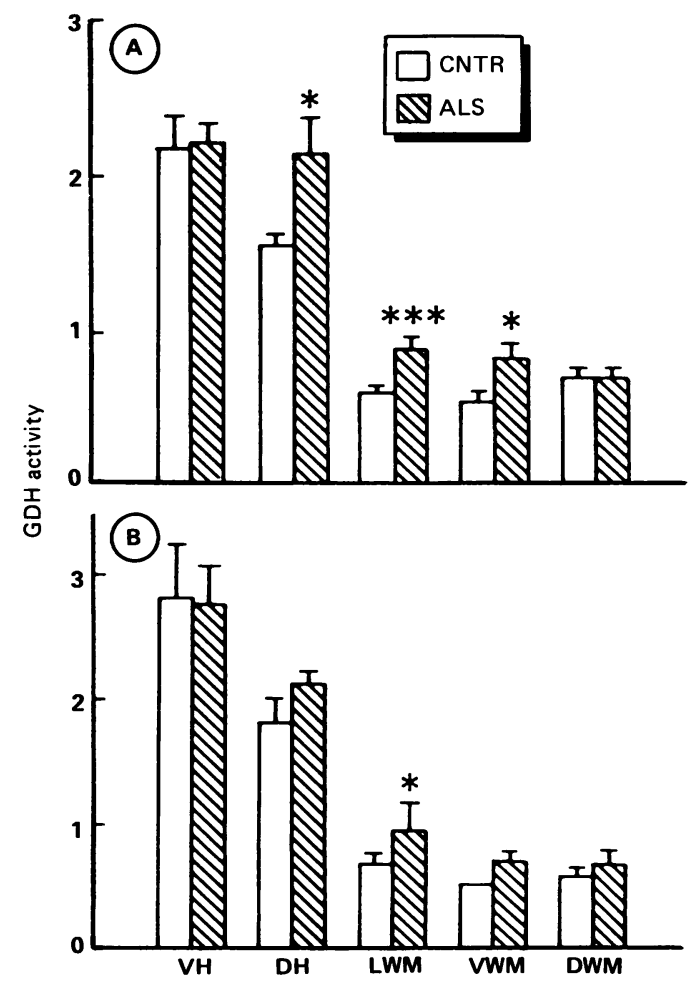

Figure $2 \mathrm{GDH}$ activity in $\mu \mathrm{mol} / \mathrm{h} / \mathrm{mg}$ wet weight, mean (SEM) in cervical (a) and lumbar (b) spinal cord. Open bars: controls ( $n=10$ in cervical, $n=6$ in lumbar spinal cord), hatched bars: $A L S$ patients $(n=7$ in cervical, $n=4$ in lumbar spinal cord). ${ }^{\star} p<0.02$; $\star \star p<0.01 ; \star \star \star p p<0.002$ (Student's t test). Abbreviations as in fig 1 . 


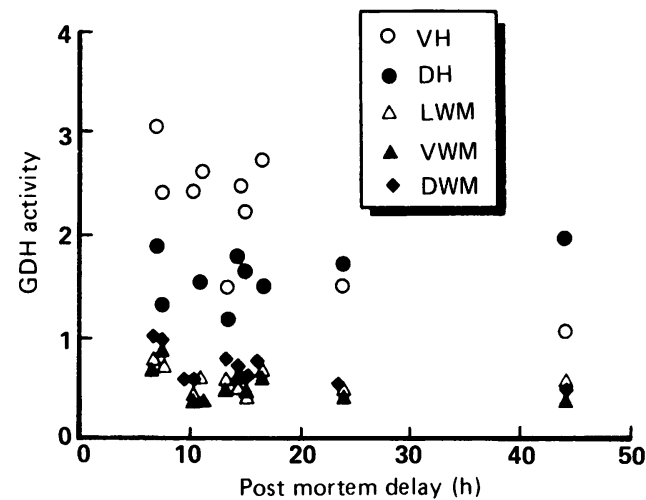

Figure 3 Single values of GDH activity in five regions of normal cervical spinal cord plotted against death-tofreezing intervals $(h)$. Correlation coefficient for $V H$ :

$-0.775(p<0.01) ; D H: 0.522(n s) ; L W M:-0.271$ (ns); VWM: $-0.521(n s)$; DWM: -0.651

$(p<0.05) ; n=10$. Abbreviations as in fig 1 .

matter, GDH activity reached $25-30 \%$ of ventral horn levels (fig 2a). In the control group, enzyme activity appeared to be independent of age or sex, but a weak correlation was found between post mortem delay and GDH activity in two cervical regions (fig 3 ). In the cervical spinal cord of ALS patients, GDH activity in ventral grey matter and white matter corresponding to the dorsal columns was at control levels (fig 2a). GDH activity was considerably increased in ALS patients in the lateral white matter comprising the crossed corticospinal and the posterior spinocerebellar tracts. Mean (SEM) GDH activity in the ALS group was $151(14) \%$ of controls $(p<0.01)$. An almost identical increase in GDH activity [151 (16)\%

Table Cervical spinal cord

\begin{tabular}{|c|c|c|c|c|c|}
\hline & $V H$ & $D H$ & $L W M$ & $V W M$ & $D W M$ \\
\hline $\begin{array}{l}\text { TAU } \\
\text { Control } \\
\text { ALS }\end{array}$ & $\begin{array}{l}2.32(0.49) \\
2.23(0.22)\end{array}$ & $\begin{array}{l}1 \cdot 71(0.13) \\
2 \cdot 13(0.19)\end{array}$ & $\begin{array}{l}1.42(0.16) \\
2.12(0.64)^{\star \star}\end{array}$ & $\begin{array}{l}1.52(0.14) \\
2.08(0.19)^{\star}\end{array}$ & $\begin{array}{l}1 \cdot 89(0.15) \\
2 \cdot 16(0.25)\end{array}$ \\
\hline $\begin{array}{l}\text { ASP } \\
\text { Control } \\
\text { ALS }\end{array}$ & $\begin{array}{l}2.63(0.38) \\
1.91(0.23)\end{array}$ & $\begin{array}{l}2.52(0.36) \\
1.76(0.38)\end{array}$ & $\begin{array}{l}1.28(0.11) \\
1.07(0.19)\end{array}$ & $\begin{array}{l}1.17(0.10) \\
0.84(0.21)\end{array}$ & $\begin{array}{l}1.83(0.20) \\
1.46(0.31)\end{array}$ \\
\hline $\begin{array}{l}\text { GLU } \\
\text { Control } \\
\text { ALS }\end{array}$ & $\begin{array}{l}6.69(0.74) \\
5.77(0.51)\end{array}$ & $\begin{array}{l}7 \cdot 13(0.63) \\
5.55(0.82)\end{array}$ & $\begin{array}{l}3.86(0.32) \\
3.29(0.23)\end{array}$ & $\begin{array}{l}3.66(0.20) \\
2.89(0.37)\end{array}$ & $\begin{array}{l}5.27(0.34) \\
4.13(0.67)\end{array}$ \\
\hline $\begin{array}{l}\text { GLY } \\
\text { Control } \\
\text { ALS }\end{array}$ & $\begin{array}{l}3.69(0.37) \\
3.29(0.32)\end{array}$ & $\begin{array}{l}3.44(0.20) \\
2.88(0.37)\end{array}$ & $\begin{array}{l}2 \cdot 36(0 \cdot 16) \\
2 \cdot 26(0 \cdot 12)\end{array}$ & $\begin{array}{l}2.64(0.06) \\
2.21(0.25)\end{array}$ & $\begin{array}{l}2.61(0.13) \\
2.09(0.34)\end{array}$ \\
\hline $\begin{array}{l}\text { GABA } \\
\text { Control } \\
\text { ALS }\end{array}$ & $\begin{array}{l}0.78(0.11) \\
0.70(0.07)\end{array}$ & $\begin{array}{l}0.77(0.08) \\
0.83(0.12)\end{array}$ & $\begin{array}{l}0.24(0.01) \\
0.20(0.01)\end{array}$ & $\begin{array}{l}0.41(0.02) \\
0.33(0.03)\end{array}$ & $\begin{array}{l}0.23(0.02) \\
0.20(0.04)\end{array}$ \\
\hline $\begin{array}{l}\text { Lumbar } s p \\
\text { TAU } \\
\text { Control }\end{array}$ & & & & & \\
\hline ALS & & 1.23 & 1.65 & $1.60(0.14)$ & $1.19(0.08)$ \\
\hline $\begin{array}{l}\text { ASP } \\
\text { Control } \\
\text { ALS }\end{array}$ & $\begin{array}{l}2.73(0.37) \\
1.35(0.30)^{\star}\end{array}$ & $\begin{array}{l}2.24(0.22) \\
1.49(0.18)^{\star}\end{array}$ & $\begin{array}{l}1.55(0.10) \\
0.80(0.11) \dagger\end{array}$ & $\begin{array}{l}1.38(0.04) \\
0.88(0.17)^{\star \star}\end{array}$ & $\begin{array}{l}1.28(0.13) \\
1.01(0.08)\end{array}$ \\
\hline $\begin{array}{l}\text { GLU } \\
\text { Control } \\
\text { ALS }\end{array}$ & $\begin{array}{l}7.19(0.81) \\
4.33(0.57)^{\star}\end{array}$ & $\begin{array}{l}6.54(0.70) \\
4.30(0.49)\end{array}$ & $\begin{array}{l}4.28(0.29) \\
2.68(0.09)^{\star \star}\end{array}$ & $\begin{array}{l}3.90(0.32) \\
2 \cdot 72(0.27)^{\star}\end{array}$ & $\begin{array}{l}4.03(0.39) \\
3.50(0.29)\end{array}$ \\
\hline $\begin{array}{l}\text { GLY } \\
\text { Control } \\
\text { ALS }\end{array}$ & $\begin{array}{l}3.64(0.40) \\
2.42(0.12)^{\star}\end{array}$ & $\begin{array}{l}3.00(0.26) \\
2.18(0.06)^{\star}\end{array}$ & $\begin{array}{l}2.30(0.20) \\
1.74(0.16)\end{array}$ & $\begin{array}{l}2.65(0.18) \\
2.25(0.08)\end{array}$ & $\begin{array}{l}2.18(0.20) \\
1.89(0.18)\end{array}$ \\
\hline $\begin{array}{l}\text { GABA } \\
\text { Control } \\
\text { ALS }\end{array}$ & $\begin{array}{l}0.82(0.17) \\
0.52(0.09)\end{array}$ & $\begin{array}{l}0.89(0.23) \\
0.75(0.18)\end{array}$ & $\begin{array}{l}0.55(0.09) \\
0.42(0.02)\end{array}$ & $\begin{array}{l}0.47(0.03) \\
0.35(0.05)\end{array}$ & $\begin{array}{l}0.44(0.05) \\
0.32(0.07)\end{array}$ \\
\hline
\end{tabular}

Taurine (TAU), aspartate (ASP), glutamate (GLU), glycine (GLY) and gamma-aminobutyric acid (GABA) in cervical and lumbar spinal cord (in $\mu \mathrm{mol} / \mathrm{g}$ wet tissue); mean (SEM). Cervical spinal cord: ALS $n=7$; controls $n=10$ except for aspartate values (ALS $n=5$; controls ${ }_{\star \star} \mathrm{p}<0.02 ; \dagger \mathrm{p}<0.002$ (Student's t test). Abbreviations as in fig 1 . of control levels; $p<0.02$ ] was observed in the ventral white matter, an area mainly composed of the anterior corticospinal, the tectospinal and the medial reticulospinal tracts. A significant increase in GDH activity was also noted in the dorsal horn of ALS affected spinal cords, the activity being $138 \%(12) \%$ of controls $(\mathrm{p}<0.02)$.

Similar increases in GDH activity were found in the lumbar enlargement of ALS spinal cord, although changes appeared to be less pronounced (fig $2 b$ ). In three ALS cases, both cervical and lumbar enlargements were available for study. Changes in GDH activity in lumbar segments paralleled the increases measured in corresponding cervical regions (data not shown).

In one patient with progressive spinal atrophy, that is without clinical or histopathological signs of corticospinal tract involvement, GDH activity was within the normal range in all lumbar regions investigated.

No changes in protein concentrations were detectable in the ALS group (data not shown).

\section{NEUROTRANSMITTER AMINO ACIDS}

The concentrations of glutamate, aspartate, taurine, glycine and gamma-aminobutyric acid (GABA) in cervical segments 6 and 7 and in the lumbar enlargement of ALS and control spinal cords are shown in the table. Levels of taurine, glutamate, glycine and GABA showed no correlation with death-to-freezing intervals in control spinal cord. Aspartate concentrations were positively correlated with post mortem delays (dorsal horn: $r=0.669 \mathrm{p}<0.05$; ventral white matter: $r=0.729 \mathrm{p}<0.02$; dorsal white matter: $r=0.664 p<0.05)$. We therefore compared aspartate levels in ALS and control patients that were matched for post mortem delay [controls: 13 (2) hours; ALS: 14 (3) hours; p $<0.91]$.

Significant reductions in glutamate were found in ALS lumbar spinal cord in the ventral horn [60 (8)\% of controls; $p<0.05]$ and in lateral and ventral white matter [63 (2)\%; $\mathrm{p}<0.01$ and $70(7) \% ; \mathrm{p}<0.05$, respectively]. The glutamate values in the ventral white matter of all four ALS cases were outside the lower range of control values; this was also the case in the ventral horn in three of the four cases analysed. A tendency towards subnormal glutamate levels $(66-86 \%$ of controls) was detectable in all other regions analysed, both lumbar and cervical. Both spinal enlargements were available for study from three ALS patients; the degree of glutamate reduction in corresponding cervical and lumbar parts correlated significantly (data not shown).

No correlation was found between glutamate levels and GDH activity.

Aspartate levels were significantly reduced in the lumbar spinal cord, ranging from $50(11) \%$ to $67(8) \%$ of control values (table). In ALS cervical spinal cords, aspartate concentrations showed a tendency to be reduced in all areas investigated.

Taurine concentration was increased in lateral white [149 (8)\% of controls; $p<0.01]$ 
and in ventral white matter [137 (11)\%; $\mathrm{p}<0.05]$ of cervical segments (table). Quantitatively comparable, although no significant changes were found in corresponding lumbar regions $[146(23) \%$ of control in lateral white; $142(12) \%$ in ventral white matter]. Apart from a reduction in glycine in lumbar dorsal and ventral grey, no major changes were detected for the inhibitory neurotransmitters glycine and GABA.

\section{Discussion}

GDH

Our investigation shows an increase in GDH activity in discrete anatomic subdivisions of cervical and lumbar spinal cord of ALS patients compared with non-neurological controls. Apart from an early histochemical study, ${ }^{17}$ we are not aware of any previous reports on GDH activity in human spinal cord. Given the longer death-to-freezing interval in ALS cervical samples and the slight decrease in GDH activity with increasing post mortem delay (fig 3), the amount of changes in enzyme activity in ALS is presumably underestimated. As we found no increase in GDH in the ventral grey matter, the reported changes are not likely to be due to tissue shrinkage. The total protein content in ALS was normal, suggesting that the increase in $\mathrm{GDH}$ is a specific change.

GDH is a mitochondrial enzyme that catalyses the inter-conversion of alphaketoglutarate and glutamate, connecting carbohydrate and amino acid metabolism. ${ }^{18}$ It is thought to act mainly in the direction of glutamate synthesis and is thus likely to play an important role in ammonia fixation. ${ }^{18} 19$ Immunohistochemical studies suggests a collocalisation of GDH and glial fibrillary acidic protein, a marker of astroglia cells. ${ }^{2021}$ The finding of an augmentation in GDH in affected white matter comprising the corticospinal tracts supports the proposed relationship between reactive gliosis and enhanced GDH activity. ${ }^{172}$ Conversely, the lack of changes in the ventral horn and the increase in enzyme activity in the dorsal horn, where pathological abnormalities are minor, argue against such an explanation. Immunocytochemical visualisation of GDH-containing structures should clarify this question.

CHANGES IN TAURINE, GLYCINE, ASPARTATE AND GLUTAMATE

In human brain at necropsy, the concentrations of taurine and glutamate are assumed to reflect the in vivo levels, while glycine, GABA and aspartate are known to increase post mortem. ${ }^{23}$

The increased levels of taurine found in lateral and ventral white matter of cervical spinal cords in ALS are in agreement with previous observations in whole segments of spinal cord and motor cortex of ALS patients. ${ }^{24}$ Since the neurobiological functions of taurine are as yet poorly understood, the implications of this finding are not known.

Glycine is contained predominantly in spinal interneurons, exerting an overall inhibitory effect on motor neurons which are believed to be glycinoceptive. It is uncertain whether loss of spinal interneurons observed in $\mathrm{ALS}^{25}$ accounts for the reduced glycine levels reported here. Possibly, the reduction of glycine in the lumbar grey matter reflects enhanced release of the transmitter resulting in elevated glycine concentrations in the cerebrospinal fluid of ALS patients. ${ }^{26}$

Reductions of excitatory amino acid neurotransmitters have previously been found in cortical and various subcortical areas including whole segments of cervical and lumbar spinal cord. ${ }^{67}$ This study suggests that these changes do not correspond to the known pattern of neuronal loss in ALS spinal cord but show a homogenous distribution in all subregions analysed, consistent with the theory of a generalised abnormality of glutamate metabolism in this disorder. Whether these changes are specific for ALS needs to be assessed by comparable studies in other forms of motor neuronal loss, for example poliomyelitis, and in patients that were wasted and immobile due to non-neurological disease.

A recent study reported on an increase of glutamate and aspartate in the cerebrospinal fluid of ALS patients, ${ }^{27}$ suggesting enhanced release of these substances in spinal tissue that might lead to excess levels of glutamate in the synaptic area and finally to a depletion of the steady-state stores of this amino acid.

What could be the triggering event for this theory of dysfunction of glutamate release in ALS spinal cord? In agreement with indirect neurophysiological evidence, recent studies on synaptosomes prepared from rat hippocampus have provided direct evidence for a presynaptic inhibitory action of acetylcholine on glutamate release. ${ }^{28}{ }^{29}$ Possibly, an initial loss, or weakening of cholinergic transmission in ALS spinal cord could reduce this inhibitory influence resulting in enhanced release of glutamate from primary afferent fibres and terminals of the corticospinal tracts. The consequent excitotoxic damage would affect primarily (cholinergic) motor neurons known to be particularly vulnerable, ${ }^{30}$ thus triggering a selfsustaining degenerative process. If proved correct, this mechanism could represent a general aetiological principle of neurodegenerative damage in the CNS.

We thank Drs E M Markis, $M$ Schmidbauer and $K$ Jellinger for providing post mortem tissue and histopathological assessment of ALS patients. SM was supported by Deutscher Akademischer Austauschdienst, FRG, and the Anton Dreher-Found, University of Vienna, Austria; PNL was supported by the Motor Neurone Disease Association of Great Britain. We also thank Professor Heide Hörtnagl and Dr Michael Berger for their helpful discussions and comments on the manuscript.

1 Tandan R, Bradley WG. Amyotrophic lateral sclerosis: P1. Clinical features, pathology and ethical issues in management. Ann Neurol 1985;250:394-7.

2 Gillberg PG, Aquilonius SM, Eckernas SA, et al. Choline acetyltransferase and substance $P$-like immunoreactivity in the human spinal cord: changes in amyotrophic latera sclerosis. Brain Res 1982;250:394-7.

3 Nagata Y, Okuya M, Watanabe R, et al. Regional distribution of cholinergic neurons in human spinal cord transections in patients with and without motor neurone disease. Brain Res 1982;244:223-9.

4 Plaitakis A, Caroscio JT. Abnormal glutamate metabolism in amyotrophic lateral sclerosis. Ann Neurol 1987;22:575-9. 5 Robinson N. Chemical changes in the spinal cord in 
Friedreich's ataxia and in motor neurone disease. $J$ Neurol Neurosurg Psychiatry 1986;31:330-3.

6 Perry TL, Hansen S, Jones K. Brain glutamate deficiency in amyotrophic lateral sclerosis. Neurology 1987;37:1845-8.

7 Plaitakis A, Constantakakis E, Smith J. The neurotoxic amino acids glutamate and aspartate are altered in the spinal cord and brain in amyotrophic lateral sclerosis. $A n n$ Neurol 1988;24:446-9.

8 Duvoisin RC, Chokroverty S, Lepore F, et al. Glutamate dehydrogenase deficiency in patients with olivopontocerebellar atrophy. Neurology 1983;33:1322-6.

9 Finocciaro G, Taroni F, DiDonato S. Glutamate dehydrogenase in olivopontocerebellar atrophies: Leucocytes, fibroblasts and muscle mitochondria. Neurology 1986;36:550-3.

10 Plaitakis A, Berl S, Yahr MD. Neurological disorders associated with deficiency in glutamate dehydrogenase. Ann Neurol 1984;15:144-53.

11 Hugon J, Tabaraud F, Rigaud M, Vallat JM, Dumas $M$. Glutamate dehydrogenase and aspartate aminotransferase in leukocytes of patients with motor neuron disease. Neurology 1989;39:956-8.

12 Aubby D, Saggu HK, Jenner P, et al. Leukocyte glutamate dehydrogenase activity in patients with degenerative neurological disorders. J Neurol Neurosurg Psychiatry 1988;51:893-902.

13 Duvoisin RC, Nicklas WJ, Ritchie V, et al. Low leukocyte glutamate dehydrogenase activity does not correlate with a particular type of multiple system atrophy. $J$ Neurol particular type of multiple system
Neurosurg Psychiatry 1988;51:1508-11.

14 Schmidt E. Glutamate dehydrogenase UV-assay. In: Bergmeyer ed. Methods of enzymatic analysis. 2nd ed. New York: Academic Press, 1974:650-9.

15 Schmid R, Hong JS, Meek $L$, et al. The effect of kainic acid on the hippocampal content of putative transmitter amino acids. Brain Res 1980;200:355-62.

16 Lowry OH, Rosenbrough NJ, Farr AL, et al. Protein measurement with the folin phenol reagent. J Biol Chem 1951;193:265-75.

17 Osterberg OP, Wattenberg $L W$. Oxidative histochemistry of reactive astrocytes. Arch Neurol 1962;7:211-18.

18 Kvamme E. Deaminases and amidases. In: Lajtha A, ed.
Handbook of neurochemistry, 2nd ed, vol 4. New York: Plenum Press, 1983:85-105.

19 Chee PY, Dahl JL, Fahien LA. The purification and properties of rat brain glutamate dehydrogenase. $J$ Neuro-

20 Aoki C, Milner TA, Sheu KFR, et al. Regional distribution of astrocytes with intense immunoreactivity for glutamate dehydrogenase in rat brain: Implications for neuron-glia interactions and glutamate transmission. J Neurosci 1987 7:2214-31.

21 Kaneko T, Akiyama H, Mizuno N. Immunohistochemical demonstration of glutamate dehydrogenase in astrocytes. Neurosci Lett 1987;77:171-5.

22 Bird ED, Gale JS, Spokes EG. Huntington's chorea: postmortem activity of enzymes involved in cerebral glucose mortem activity of enzymes involved in ce

23 Perry TL, Hansen S, Gandham SS. Postmortem changes of amino compounds in human and rat brain. $J$ Neurochem amino compounds

24 Yoshino Y, Koike H, Akai K. Free amino acids in motor cortex of amyotrophic lateral sclerosis. Experientia 1979;35:219-20.

25 Swash M, Leader M, Brown A, Swettenham KW. Focal loss of anterior horn cells in the cervical cord in motor neuron disease. Brain 1986;109:939-52.

26 De Belleroche J, Recordati A, Clifford Rose F. Elevated levels of aminoacids in the CSF of motor neuron disease patients. Neurochem Pathol 1984;2:1-6.

27 Rothstein JD, Tsai G, Kuncl RW, et al. Excitatory amino acids in amyotrophic lateral sclerosis (Abstr). Soc Neuroscience 1989.15:840.

28 Marchi M, Bocchieri P, Garbarino L, et al. Muscarinic inhibition of endogenous glutamate release from rat inhibition of endogenous glutamate release from rat
hippocampus synaptosomes. Neurosci Lett 1989;96: hippocamp 229.

29 Marchi M, Raiteri M. Interaction acetylcholine-glutamate in rat hippocampus: Involvement of two subtypes of muscarinic receptors. J Pharmacol Exp Ther 1989; 248:1255-60.

30 Hugon J, Vallat JM, Spencer PS, Leboutet MJ, Barthe D Kainic acid early and delayed degenerative neuronal changes in rat spinal cord. Neurosci Lett 1989;104:258-62. 